\title{
Pengaruh Hypnotherapy Terhadap Penurunan Kadar Glukosa Darah Pada Penderita Diabetes Melitustipe-2 Di Klinik Miftahussyifa Kota Bengkulu
}

\author{
Suwanto $^{1}$, Yusran Hasymi ${ }^{2}$, Hasan Husin ${ }^{3}$ \\ ${ }^{1}$ Prodi S1 keperawatan Fakultas KesehatanUniversitas Muhamadiyah Bengkulu \\ ${ }^{2}$ Prodi D3 Keperawatan FMIPA Universitas Bengkulu \\ ${ }^{3}$ Fakultas KesehatanUniversitas Muhamadiyah Bengkulu \\ Email: yusranhasymi@yahoo.com
}

\begin{abstract}
Abstrak
Diabetes mellitus merupakan suatu kelompok penyakit metabolic dengan karakteristik hiperglikemia yang terjadi karena kelainan sekresi insulin, kerja insulin, atau kedua-duanya. Kasus diabetes melitus yang terbanyak adalah diabetes melitus tipe-2. Tujuan penelitian inia dalah untuk mengetahui pengaruh hypnotherapy terhadap penurunan kadar glukosa darah pada penderita diabetes melitus tipe-2 di Klinik Miftahussyifa Kota Bengkulu. Desain penelitian yang digunakan adalah quasi eksperimen design dengan non equivalent control group design. Metode sampling yang digunakan adalah purposive sampling. Sampel yang diambil sebanyak 62 responden. Instrumen dalam penelitian ini menggunakan alat single stick. Kelompok eksperimen diberikan perlakuan terapi standar berupa terapi bio energy dan hypnotherapy, sementara kelompok control hanya diberikan perlakuan terapi standar berupa terapi bio energi. Dari hasil penelitian, analisa univariat didapatkan hasil rata-rata kadar glukosa darah sebelum perlakuan sebesar 234,67 mg/dl dan setelah perlakuan sebesar 194,67 $\mathrm{mg} / \mathrm{dl}$. Analisis bivariat berdasarkan hasil uji Wilcoxon Signed Ranks Test diperoleh nilai $p$ value 0.002 ( $p$ value $<0.05$ ). Artinya ada pengaruh hypnotherapy terhadap penurunan kadar glukosa darah pada penderita diabetes melitus tipe-2 di Klinik Miftahussyifa Kota Bengkulu. Penelitian ini merekomendasikan kepada profesi keperawatan untuk dapat menerapkan hypnotherapy sebagai terapi alternatif atau terapi komplementer non farmakologis yang dapat digunakan untuk menurunkan kadar glukosa darah pada penderita diabetes melitus tipe-2.
\end{abstract}

Kata Kunci : Hypnotherapy, diabetes melitus tipe-2, kadar glukosa darah 


\title{
The Effect of Hypnotherapy on Decreasing Blood Glucose Levels in Melitustipe-2 Diabetes Patients in Miftahussyifa Clinic Bengkulu City
}

\begin{abstract}
Diabetes mellitus is a group of metabolic diseases characterized by hyperglycemia that occurs due to abnormal insulin secretion, insulin action, or both. Most cases of diabetes mellitus are type 2 diabetes mellitus. The purpose of this study was to determine the effect of hypnotherapy on reducing blood glucose levels in patients with type 2 diabetes mellitus at Miftahussyifa Clinic, Bengkulu City. The research design used was a quasi-experimental design with a non equivalent control group design. The sampling method used was purposive sampling. Samples taken were 62 respondents. The instrument in this study used a single stick tool. The experimental group was given a standard therapy treatment in the form of bio energy therapy and hypnotherapy, while the control group was only given a standard therapy treatment in the form of bio energy therapy. From the results of the study, univariate analysis showed an average blood glucose level before treatment of $234.67 \mathrm{mg} / \mathrm{dl}$ and after treatment of $194.67 \mathrm{mg} / \mathrm{dl}$. Bivariate analysis based on the Wilcoxon Signed Ranks Test results obtained p value 0.002 ( $\mathrm{p}$ value <0.05). This means that there is an influence of hypnotherapy on decreasing blood glucose levels in patients with type 2 diabetes mellitus at Miftahussyifa Clinic, Bengkulu City. This study recommends that the nursing profession be able to apply hypnotherapy as an alternative therapy or nonpharmacological complementary therapy that can be used to reduce blood glucose levels in people with type 2 diabetes mellitus.
\end{abstract}

Keywords: Hypnotherapy, type 2 diabetes mellitus, blood glucose level

\section{Pendahuluan}

Penyakit tidak menular sudah menjadi masalah kesehatan masyarakat, baik secara global, regional, nasional dan lokal. Salah satu penyakit tidak menular yang menyita banyak perhatian adalah Diabetes Melitus (Kemenkes RI, 2013). Menurut American Diabetes Association (ADA) tahun 2010, diabetes melitus merupakan suatu kelompok penyakit metabolik dengan karakteristik hiperglikemia yang terjadi karena kelainan sekresi insulin, kerja insulin, atau keduaduanya (Perkeni, 2011).

\begin{abstract}
Berdasarkan sebuah laporan studi mengenai penyakit diabetes oleh Direktur Jenderal Pengendalian Penyakit dan Penyehatan Lingkungan (Dirjen P2PL) Kemenkes RI, menyampaikan bahwa global status report on NCD World Health Organization (WHO) tahun 2010 melaporkan $60 \%$ penyebab kematian semua umur di dunia adalah karena penyakit tidak menular. Diabetes melitus menduduki peringkat ke-6 sebagai penyebab kematian. Sekitar 1,3 juta orang meninggal akibat diabetes dan $4 \%$ meninggal sebelum usia 70 tahun.
\end{abstract}


Di Propinsi Bengkulu jumlah penderita Diabetes Melitus tipe-2 yang berobat di Poliklinik Penyakit Dalam RSUD Dr. M. Yunus Bengkulu tahun 2011 sebanyak 3.330 orang, tahun 2012 sebanyak 3.170 orang dan tahun 2013 sebanyak 2.370 orang. Berdasarkan kasus baru, jumlah penderita Diabetes Melitus tipe-2 yang berobat di Poliklinik Penyakit Dalam RSUD Dr. M. Yunus Bengkulu tahun 2012 mengalami peningkatan yang cukup signifikan yaitu $106,14 \%$ atau sebanyak 369 orang dibandingkan pada tahun 2011 yang hanya sebanyak 179 orang dan pada tahun 2013 mengalami penurunan 14,95\% atau sebanyak 321 orang (RSUD Dr. M. Yunus Bengkulu, 2014).

Peningkatan prevalensi DM tipe2 diatas menunjukan pentingnya upaya pencegahan. Pencegahan DM tipe-2 adalah dengan mengupayakan kadar glukosa darah dalam tubuh menjadi normal. Menurut Waspadji, (2007, dalam Misdarina \& Ariani, 2012) bahwa upaya untuk menurunkan kadar gula darah yaitu melalui empat pilar penatalaksanaan DM seperti edukasi, perencanaan makan, latihan jasmani dan terapi farmakologi. Selain empat pilar penatalaksanaan DM diatas, upaya lain yang dapat digunakan untuk mengendalikan prevalensi diabetes melitus tipe-2 adalah dengan program manajemen stres (Surwit Dkk, 2013).

Secara luas telah diakui bahwa stres memiliki dampak negatif pada kesehatan. Pengalaman stres dapat dikaitkan dengan pelepasan hormon counteregulatory dan mobilisasi energi, sering mengakibatkan kadar glukosa yang tinggi. Selain itu stres dapat menganggu kontrol diabetes secara tidak langsung melalui efek pada diet, olahraga, dan prilaku perawatan diri lainnya. Beberapa studi menunjukkan hubungan stres dengan kontrol glikemik pada sampel pasien dengan diabetes melitus tipe-2. Stres dapat dikelola melalui program manajeman stres atau melalui pemberian obat anxiolytik. Kedua jenis intervensi ini telah dilaporkan untuk memperbaiki kontrol glikemik pada pasien dengan diabetes melitus tipe-2 (Surwit Dkk, 2013).

Klinik Miftahussyifa kota Bengkulu adalah salah satu kegiatan dibawah naungan Yayasan Miftahussyifa Bengkulu yang telah beroperasi sejak tahun 2009 dan telah terdaftar di Kementrian Kesehatan Kota Bengkulu. Berdasarkan wawancara peneliti dengan terapis di klinik tersebut, bahwa diabetes melitus tipe-2 merupakan penyakit terbanyak ke-2 yang prevalensinya meningkat terus. Jumlah penderita diabetes melitus yang berobat jalan tercatat pada tahun 2011 sebanyak 1.078 orang, tahun 2012 sebanyak 1.520 orang dan tahun 2013 sebanyak 1.971 orang. Pada bulan Januari 2014 juga tecatat sebanyak 131 orang yang berobat jalan diklinik tersebut (Klinik Miftahussyifa Kota Bengkulu, 2014). 
Berdasarkan hasil survei pendahuluan yang peneliti lakukan di klinik Miftahussyifa Kota Bengkulu, aplikasi hypnotherapy dilakukan terbatas hanya untuk memotivasi pasien, anestesi pada saat melakukan pembekaman maupun akupuntur dan manajemen stres. Untuk pasien diabetes melitus tipe-2 masih belum dilakukan hypnotherapy.

Berdasarkan uraian diatas, maka peneliti tertarik untuk melakukan penelitian guna mengetahui pengaruh hypnotherapy terhadap penurunan kadar glukosa darah pada penderita diabetes melitus tipe-2 di Klinik Miftahussyifa Kota Bengkulu tahun 2014.

\section{Metode Penelitian}

Jenis penelitian yang digunakan dalam penelitian ini adalah quasi-eksperimen design dengan nonequivalent control group design. Dalam desain ini terdapat dua kelompok, yaitu kelompok eksperimen dan kelompok kontrol. Observasi dilakukan secara dua kali yaitu sebelum dan sesudah eksperimen. Observasi yang dilakukan sebelum eksperimen $\left(\mathrm{O}_{1}\right)$ disebut pre-test dan observasi yang dilakukan sesudah eksperiman $\left(\mathrm{O}_{2}\right)$ disebut post-test. Pada desain ini kelompok eksperimen maupun kelompok kontrol tidak dipilih secara random (Sugiyono, 2011). Penelitian ini dilaksanakan di Klinik Miftahussyifa Kota Bengkulu dari tanggal 20 April sampai tanggal 20 Mei tahun 2014. Populasi dalam penelitian ini adalah seluruh klien dengan gangguan sistem endokrin yang terdiagnosa diabetes melitus tipe-2 dan sedang menjalani pengobatan di Klinik Miftahussyifa Kota Bengkulu pada tanggal 20 April sampai tanggal 20 Mei tahun 2014. Dalam mengambil sampel penelitian ini menggunakan tenik "Purposive sampling", yaitu teknik penentuan sampel dengan pertimbangan tertentu sesuai dengan yang dikehendaki peneliti. Kriteria inklusi sampel yang akan dilakukan penelitian adalah :

1. Bersedia menjadi responden dan mau mengikuti hypnotherapy.

2. Pasien yang terdiagnosa diabetes melitus tipe-2.

3. Pasien yang terdiagnosa diabetes melitus tipe-2 dengan tingkat umur yang relatif sama yaitu 30 sampai 40 tahun.

4. Pasien yang terdiagnosa diabetes melitus tipe-2 dengan tingkat pendidikan yang relatif sama yaitu SMA/sederajat.

Untuk mendapatkan sejumlah populasi (dimana rata-rata pasien perbulan berjumlah 164 orang) yang akan dijadikan sampel dilakukan dengan rumus Slovin (Nursalam, 2008, dalam Harefa, Manurung \& Nainggolan, 2010) yaitu sebagai berikut:

$$
n=\frac{N}{1+N(d)^{2}}
$$

Keterangan:

$$
\begin{array}{ll}
n & =\text { Besar Sampel } \\
\mathrm{N} & =\text { Besar Populasi } \\
\mathrm{d} & =\text { Tingkat Signifikan }(0,1)
\end{array}
$$




$$
\begin{aligned}
& n=\frac{164}{1+164(0,1)^{2}} \\
& n=\frac{164}{1+164(0,01)} \\
& n=\frac{164}{1+1,64} \\
& n=\frac{164}{2,64} \\
& n=62,12
\end{aligned}
$$

Adapun instrumen yang digunakan dalam penelitian ini adalah mentode pengukuran. Pengukuran adalah suatu cara sistematis untuk menentukan jumlah, ukuran atau memberi label pada objek-objek dan atribut yang dimilikinya. Pengukuran merupakan aplikasi dari suatu definisi operasional yang bertujuan mengkaji suatu nilai dari variabel yang sedang diteliti. Hasil dari pengukuran adalah data penelitian yang didapat dari subyek (Sugiono, 2011). Metode pengukuran yang dimaksud dalam penelitian ini adalah menggunakan alat single stick untuk mengukur kadar glukosa darah sewaktu. Kadar glukosa darah sewaktu yang bukan DM, belum pasti DM dan DM dapat dilihat pada tabel 1 berikut ini:

\section{Tabel 1. Kadar glukosa darah sewaktu}

\begin{tabular}{|l|l|l|c|}
\hline & \multicolumn{1}{|c|}{ Bukan DM } & Belum pasti DM & \multicolumn{1}{c|}{ DM } \\
\hline Plasma vena & $<100 \mathrm{mg} / \mathrm{dl}$ & $100-199 \mathrm{mg} / \mathrm{dl}$ & $\geq 200 \mathrm{mg} / \mathrm{dl}$ \\
\hline Darah kapiler & $<90 \mathrm{mg} / \mathrm{dl}$ & $90-199 \mathrm{mg} / \mathrm{dl}$ & $\geq 200 \mathrm{mg} / \mathrm{dl}$ \\
\hline
\end{tabular}

Sumber: PERKENI, 2006, dalam Tarwoto Dkk, 2012

Proses pengumpulan data sebelum mengadakan penelitian, peneliti mengadakan observasi atau survei awal di Klinik Miftahussyifa Kota Bengkulu untuk mengetahui keadaan pasien yang terdiagnosa diabetes melitus tipe-2. Data yang digunakan dalam penelitian ini adalah data primer, dan dalam pengumpulan data ini peneliti dibantu oleh para terapis di Klinik Miftahussyifa Kota Bengkulu untuk mendapatkan data pasien yang terdiagnosa diabetes melitus tipe-2. Pengumpulan data dilakukan pada tanggal 20 April sampai tanggal 20 Mei tahun 2014. Dalam pelaksanaan hypnotherapy, peneliti melakukan penelitian di Klinik Miftahussyifa Kota Bengkulu, dimana dalam dua minggu pertama peneliti melakukan hypnotherapy terhadap responden yang berkunjung dan dua minggu kedua tidak melakukan hypnotherapy. Pada kelompok eksperimen, setelah ada persetujuan dari responden yang telah diberi penjelasan tentang maksud dan tujuan penelitian, kemudian responden dilakukan pengukuran kadar glukosa darah sewaktu, hasil dari pengukuran glukosa darah sewaktu tersebut sekaligus sebagai pre test. Setelah responden diberikan terapi standar berupa terapi bio energi oleh terapis di klinik tersebut kemudian responden diberi perlakuan hypnotherapy oleh peneliti yang 
terdiri dalam enam tahap. Pada kelompok kontrol, setelah ada persetujuan dari responden yang telah diberi penjelasan tentang maksud dan tujuan penelitian, kemudian responden dilakukan pengukuran kadar glukosa darah sewaktu, hasil dari pengukuran glukosa darah sewaktu tersebut sekaligus sebagai pre test dan pengukuran kembali pada hari ke tiga sebagai post test.

\section{Hasil penelitian dan pembahasan}

\section{Univariat}

Pada kelompok kontrol ini, responden hanya diberikan terapi standar berupa terapi bio energi oleh terapis di klinik tersebut tanpa diberikan perlakuan hypnotherapy oleh peneliti. Kemudian hasil dari post test dan pre test juga ditabulasi secara berpasangan. Kadar glukosa darah pada pasien diabetes melitus tipe-2 sebelum diberikan terapi standar (terapi bio energi) pada kelompok kontrol, kadar glukosa darah tertinggi menunjukkan angka $376 \mathrm{mg} / \mathrm{dl}$ dan kadar glukosa darah terendah menunjukkan angka 133 mg/dl. Kadar glukosa darah pada pasien diabetes melitus tipe-2 setelah diberikan terapi standar (terapi bio energi) pada kelompok kontrol, kadar glukosa darah tertinggi menunjukkan angka $295 \mathrm{mg} / \mathrm{dl}$ dan kadar glukosa darah terendah menunjukkan angka $115 \mathrm{mg} / \mathrm{dl}$.Hal ini menunjukkan terdapat perubahan kadar glukosa darah sebelum dan setelah diberikan terapi standar (terapi bio energi). nilai mean kadar glukosa darah responden sebelum diberikan terapi standar (terapi bio energi) sebesar 203,07 mg/dl, nilai median kadar glukosa darah responden sebelum diberikan terapi standar (terapi bio energi) sebesar $157,00 \mathrm{mg} / \mathrm{dl}$ dan nilai moduskadar glukosa darah responden sebelum diberikan terapi standar (terapi bio energi) sebesar $139 \mathrm{mg} / \mathrm{dl}$. Hasil penelitian menunjukkan bahwa nilai mean kadar glukosa darah responden setelah diberikan terapi standar (terapi bio energi) sebesar 176,07 $\mathrm{mg} / \mathrm{dl}$, nilai median kadar glukosa darah responden setelah diberikan terapi standar (terapi bio energi) sebesar 152,00 $\mathrm{mg} / \mathrm{dl}$ dan nilai moduskadar glukosa darah responden setelah diberikan terapi standar (terapi bio energi) sebesar $115 \mathrm{mg} / \mathrm{dl}$. Terdapatnya perubahan kadar glukosa darah sebelum dan setelah dilakukan terapi standar (terapi bio energi) dan hypnotherapy diketahui perubahan kadar glukosa darah tertinggi sebesar $127 \mathrm{mg} / \mathrm{dl}$ dan perubahan kadar glukosa darah terendah $7 \mathrm{mg} / \mathrm{dl}$. Dapat dilihat hasil penelitian menunjukkan bahwa nilai mean perubahan kadar glukosa darah responden setelah diberikan terapi standar (terapi bio energi) dan hypnotherapy sebesar 40,00 mg/dl, nilai median kadar glukosa darah responden setelah diberikan terapi standar (terapi bio energi) dan hypnotherapy sebesar $22,00 \mathrm{mg} / \mathrm{dl}$ dan nilai moduskadar glukosa darah responden setelah diberikan terapi standar (terapi bio energi) dan hypnotherapy sebesar $44 \mathrm{mg} / \mathrm{dl}$. 
Perubahan kadar glukosa darah sebelum dan setelah dilakukan terapi standar (terapi bio energi) diketahui perubahan kadar glukosa darah tertinggi sebesar $136 \mathrm{mg} / \mathrm{dl}$ dan perubahan kadar glukosa darah terendah $4 \mathrm{mg} / \mathrm{dl}$. Nnilai mean perubahan kadar glukosa darah responden setelah diberikan terapi standar (terapi bio energi) sebesar $27,00 \mathrm{mg} / \mathrm{dl}$, nilai median kadar glukosa darah responden setelah diberikan terapi standar (terapi bio energi) sebesar $18,00 \mathrm{mg} / \mathrm{dl}$ dan nilai moduskadar glukosa darah responden setelah diberikan terapi standar (terapi bio energi) sebesar 6 $\mathrm{mg} / \mathrm{dl}$.

\section{Analisis Bivariat}

Untuk melihat normalitas data, maka masing-masing data kadar glukosa darah sebelum dan setelah perlakuan pada kelompok eksperimen maupun kelompok kontrol dilakukan pengujian normalitas dengan menggunakan uji normalitas data dengan menggunakan KolmogorovSmirnov yang dilihat adalah tabel Shapiro-Wilk karena $<50$ responden. Kadar glukosa darah sebelum perlakuan pada kelompok eksperimen didapatkan nilai $p=$ 0,194 . Karena nilai $p>0,05$, maka diambil kesimpulan bahwa distribusi datanya normal. Sedangkan kadar glukosa darah setelah perlakuan pada kelompok eksperimen didapatkan nilai $p=0,026$. Karena nilai $p<0,05$, maka diambil kesimpulan bahwa distribusi datanya tidak normal. Karena data berdistribusi tidak normal, maka uji hipotesis yang digunakan adalah uji non parametik, dengan menggunakan uji statistik Wilcoxon Signed Ranks Test. Analisa bivariat bertujuan untuk mengetahui pengaruh terapi standar (terapi bio energi) dan hypnotherapy terhadap penurunan kadar glukosa darah pada penderita diabetes melitus tipe-2 di Klinik Miftahussyifa Kota Bengkulu. Hasil penelitian ini menunjukkan bahwa perbandingan kadar glukosa darah pada penderita diabetes melitus tipe-2 sebelum dan setelah diberikan terapi standar (terapi bio energi) dan hypnotherapy terdapat 2 (dua) responden dengan hasil kadar glukosa darah setelah diberikan terapi standar (terapi bio energi) dan hypnotherapy mengalami kenaikan daripada sebelum diberikan terapi standar (terapi bio energi) dan hypnotherapy, dan 13 responden dengan hasil kadar glukosa darah setelah diberikan terapi standar (terapi bio energi) dan hypnotherapy mengalami penurunan daripada sebelum diberikan terapi standar (terapi bio energi) dan hypnotherapy. Hasil uji Wilcoxon Signed Ranks Test diperoleh nilai signifikansi 0,002 atau signifikansi kurang dari 0,05 sehingga Ho ditolak dan Ha diterima atau didapatkan $p$ value 0,002 ( $p$ value $<0,05)$, berarti dapat disimpulkan bahwa ada pengaruh terapi standar (terapi bio energi) dan hypnotherapy terhadap penurunan kadar glukosa darah pada penderita diabetes melitus tipe-2 di Klinik Miftahussyifa Kota Bengkulu. Pada kelompok kontrol, kadar glukosa 
darah sebelum perlakuan didapatkan nilai $p=0,001$. Karena nilai $p<0,05$, maka diambil kesimpulan bahwa distribusi datanya tidak normal. Sedangkan kadar glukosa darah setelah perlakuan pada kelompok kontrol didapatkan nilai $p=0,029$. Karena nilai $p$ juga $<0,05$, maka diambil kesimpulan bahwa distribusi datanya tidak normal. Karena data berdistribusi tidak normal, maka uji hipotesis yang digunakan adalah uji non parametik, dengan menggunakan uji statistik Wilcoxon Signed Ranks Test. Analisa bivariat bertujuan untuk mengetahui pengaruh terapi standar (terapi bio energi) terhadap penurunan kadar glukosa darah pada penderita diabetes melitus tipe- 2 di Klinik Miftahussyifa Kota Bengkulu. Terdapatnya perbandingan kadar glukosa darah pada penderita diabetes melitus tipe-2 sebelum dan setelah diberikan terapi standar (terapi bio energi) terdapat 2 (dua) responden dengan hasil kadar glukosa darah setelah diberikan terapi standar (terapi bio energi) mengalami kenaikan daripada sebelum diberikan terapi standar (terapi bio energi), dan 13 responden dengan hasil kadar glukosa darah setelah diberikan terapi standar (terapi bio energi) mengalami penurunan daripada sebelum diberikan terapi standar (terapi bio energi) . Hasil uji Wilcoxon Signed Ranks Test diperoleh nilai signifikansi 0,002 atau signifikansi kurang dari 0,05 sehingga Ho ditolak dan Ha diterima atau didapatkan $p$ value 0,002 ( $p$ value $<0,05)$, berarti dapat disimpulkan juga bahwa ada pengaruh terapi standar (terapi bio energi) terhadap penurunan kadar glukosa darah pada penderita diabetes melitus tipe-2 di Klinik Miftahussyifa Kota Bengkulu.

\section{Simpulan}

Penelitian mengenai pengaruh hypnotherapy terhadap perubahan kadar glukosa darah pada penderita diabetes melitus tipe-2 di Klinik Miftahussyifa Kota Bengkulu ini bertujuan untuk mengetahui kadar glukosa darah pada penderita diabetes melitus tipe-2 sebelum dan sesudah dilakukan hypnotherapy. Dari hasil penelitian yang diperoleh, dapat peneliti simpulkan hal-hal sebagai berikut : Rata-rata kadar glukosa darah sebelum diberikan hypnotherapy sebesar $234,67 \mathrm{mg} / \mathrm{dl}$, Rata-rata kadar glukosa darah setelah diberikan hypnotherapy sebesar 194,67 mg/dl, Berdasarkan hasil uji Wilcoxon Signed Ranks Test diperoleh $p$ value kadar glukosa darah sebelum dan setelah hypnotherapy sebesar $0.002(p \quad$ value $<0.05)$ sehingga Ho ditolakdan Ha diterima berarti ada pengaruh hypnotherapy terhadappenurunankadarglukosadara hpadapenderita diabetes melitus tipe2 di KlinikMiftahussyifa Kota Bengkulu.

\section{Daftar Pustaka}

Dharma, Kelana Kusuma. (2012). Metode penelitian keperawatan panduan melaksanakan dan menerapkan hasil penelitian. Penerbit: Trans Info Media 
Gemilang, Jingga. (2013). Buku pintar manajemen stres dan emosi. Yogyakarta: Penerbit Mantra Books

Gunawan, Adi W. (2010). Hypnotherapy the art of subconscious restructuring. Jakarta: Penerbit Gramedia Pustaka Utama

Hendriyanto, Bayu., aat Sriati \& Nita Fitria. (2012). Pengaruh hypnotherapy terhadap tingkat stres mahasiswa Fakultas Ilmu Keperawatan Universitas Padjajaran Angkatan 2011. Jurnal FIK UNPAD

IBH. (2012). Hypnotherapy workshop: A jurney to the sub conscious world. Jakarta: IBH Training

Kemenkes RI. (2013). Diabetes melitus penyebab kematian nomot 6 di dunia: Kemenkes tawarkan solusi CERDIK melalui posbindu. http://www.depkes.go.id/index. php? $v w=2 \& i d=2383$. (diakses tanggal 20 Februari 2017)

Kemenkes RI. (2013). Tahun 2030 prevalensi diabetes melitus di Indonesia mencapai 21,3 juta orang.

http://www.depkes.go.id/index. php? $\mathrm{vw}=2 \& \mathrm{id}=414$. (diakses tanggal 20 Februari 2017)

Klinik Miftahussyifa Kota Bengkulu. (2014). Laporan tahunan Klinik Miftahussyifa Kota Bengkulu 2013. Bengkulu: Sekretariat

Maarifuddin, Muh Rendi \& Burhanudin. (2013). Pengaruh hypnotherapy terhadap kadar glukosa darah pasien diabetes melitus di Puskesmas Kedungwuni II Kabupaten Pekalongan tahun 2013. Jurnal STIKES Muhammadiyah Pekajangan, Pekalongan

Misadarina \& Yesi Ariani. (2012). Pengetahuan diabetes melitus dengan kadar gula darah pada pasien DM tipe 2. Jurnal FK USU

Perkeni. (2011). Konsensus pengelolaan dan pencegahan diabetes melitus tipe 2 di Indonesia 2011

Rapigawe, Irfan. (2013). Lebih dekat dengan hipnosis dan hipnotherapi.

http://www.ibhcenter.org. (diakses tanggal 22 Februari 2017)

RSUD Dr. M. Yunus Bengkulu. (2014). Laporan tahunan Rumah Sakit Umum Daerah M. Yunus Bengkulu 2013. Bengkulu: Medical Record

Setiadi. (2007). Konsep \& penulisan riset keperawatan. Yogyakarta: Penerbit Graha Ilmu

Shaleh, malikkul. (2010). Penguasaan terapi komplementar jadi nilai tambah perawat. http://www.news.unpad.ac.id/? $\mathrm{p}=28917$. (diakses tanggal 24 Februari 2017)

Sudoyo Dkk. (2010). Buku ajar ilmu penyakit dalam. Jakarta: Penerbit InternaPublishing

Sugiono. (2010). Metodelogi penelitian pendidikan pendekatan kuantitatif, 
kualitatif dan $R \& D$. Bandung:

Penerbit Alfabeta

Surwit Dkk. (2013). Stress management improves longterm glycemic control in type 2 diabetes. Jurnal American Diabetes Association

Tarwoto \& Wartonah. (2011). Kebutuhan dasar manusia dan proses keperawatan. Jakarta: Penerbit Salemba Medika

Tarwoto Dkk. (2012). Keperawatan medical bedah gangguan sistem endokrin. Jakarta: Penerbit Trans Info Media

Wang, Efendi. (2010). Dahsyatnya neohypnomagics. Depok: Penerbit Penebar Plus ${ }^{+}$

Wikipedia Bahasa Indonesia. (2014).Elektrostatik untuk terapi.http://id.wikipedia.org/w iki/Elektrostatik. (diakses tanggal 05 Juni 2017) 